\title{
OS CENTROS DE INFORMAÇÃo SOBRE MEDICAMENTOS \\ E O ACESSO E USO RACIONAL DE MEDICAMENTOS NO BRASIL À LUZ DO DIREITO SANITÁRIO
}

\author{
THE BRAZILIAN CENTERS OF DRUG INFORMATION AND \\ THE ACCESS AND RATIONAL USE OF MEDICINES IN \\ BRAZIL FROM THE PERSPECTIVE OF HEALTH LAW
}

\author{
Alexandre Augusto de Toni Sartori* \\ Silvia Beatriz Costa Czermainski**
}

\section{RESUMO}

O usuário do Sistema Único de Saúde (SUS) tem o direito constitucional ao acesso universal, individualizado e integral à assistência farmacêutica (AF). Para verificar a possível contribuição dos Centros de Informação sobre Medicamentos (CIMs) como estratégia para a garantia desse direito, analisaramse políticas públicas de saúde vigentes, aspectos sobre a via de acesso e uso racional de medicamentos, e a importância do acesso à informação. $\mathrm{O}$ trabalho apresenta abordagem qualitativa, no formato de revisão bibliográfica, contemplando pesquisa em fontes bibliográficas e eletrônicas, pesquisa e análise de documentos relacionados com políticas públicas de saúde e leitura crítica das informações coletadas à luz do direito sanitário. Foi possível verificar que (1) os CIMs não estão inseridos nas políticas farmacêuticas, embora a informação sobre medicamentos seja diretriz dessas políticas, e (2) são estratégicos para todo o campo de práticas da AF no SUS; (3) o direito pleno à saúde requer que o paciente tenha acesso a medicamentos, serviços e tecnologias disponíveis no SUS, de modo a garantir a individualidade da terapia prescrita; (4) a

(*) Especialista em Direto Sanitário, Escola de Saúde Pública do Rio Grande do Sul, Universidade do Vale do Rio dos Sinos (ESP/RS - Unisinos). Farmacêutico, Conselho Regional de Farmácia do Rio Grande do Sul/Centro de Informações sobre Medicamentos do Rio Grande do Sul. Porto Alegre/ RS - Brasil. E-mail: alexandre.aats@gmail.com.

$\left.{ }^{* *}\right)$ Mestre em Ciências Farmacêuticas, Universidade Federal do Rio Grande do Sul; Professora e Orientadora do Curso de Direito Sanitário, Escola de Saúde Pública do Rio Grande do Sul, Universidade do Vale do Rio dos Sinos (ESP/RS-Unisinos). Farmacêutica. Porto Alegre/RS - Brasil.

Texto recebido em 30.12.11. Revisado em 19.04.12. Aprovado em 27.04.12. 
garantia desse direito presume que todos os atores envolvidos tenham acesso a informações técnico-científicas disponíveis, criticamente avaliadas, sobre todos os campos de práticas e modelos terapêuticos reconhecidos pelo SUS. As propostas inclusivas apresentadas visam integrar estrategicamente os CIMs ao SUS, principalmente à AF, e podem ser berçário para revisão da atual Política Nacional de Assistência Farmacêutica, fortalecendo-a e tornando-a efetivamente universalizada e integrada com as necessidades da sociedade por informação de qualidade e pelo uso racional de terapias, produtos e serviços preconizados.

\section{Palavras-chave:}

Assistência Farmacêutica; Centros de Informação; Medicamentos; Políticas de Saúde.

\section{ABSTRACT}

Users of the Brazilian National Health System have the constitutional right to an universal, individualized and complete access to the pharmaceutical assistance. This article analyzes the Brazilian current health policies, aspects related to access and rational use of drugs and the importance of information access in order to discuss the potential contribution of the centers of drug information to the guarantee of the right to pharmaceutical assistance. This works present a qualitative approach, in a literature review format, covering research in bibliographic and electronic sources, research and analysis of documents related to public health policies and a critical review of the achieved information from the perspective of health law. It was possible to verify that (1) the centers are not included in the pharmaceutical policies, although drug information is a guideline of these policies and (2) they are strategic to the pharmaceutical assistance in the Brazilian health system; (3) the right to health demands that the patient has access to medicines, services and technology available in the health system in order to guarantee the individuality of the prescribed therapy; (4) the guarantee of this right presumes that all involved has access to scientific and evaluated information about all models and practices recognized by the health system. This paper also presents inclusive proposals aim at integrating in a strategic way the centers of drug information into the Brazilian health system, mainly in the pharmaceutical assistance aspect, and they may be a beginning to review the current Brazilian National Pharmaceutical Assistance Police, strengthening it and making it really universalized and integrated to the society requirements for quality information and rational use of therapies, products and services.

\section{Keywords:}

Drug; Health Policy; Information Centers; Pharmaceutical Assistance. 


\section{INTRODUÇÃO}

A realização da audiência pública da saúde promovida pelo Supremo Tribunal Federal (STF) em 2009 decorreu do aumento crescente de demandas judiciais para a busca do direito à saúde, principalmente a do acesso a medicamentos, negado administrativamente por gestores no Sistema Único de Saúde (SUS) ${ }^{(1),(2)}$. Na pauta das discussões, as políticas públicas de saúde vigentes foram o referencial político institucional tanto para garantir plenamente o direito constitucional de acesso universal, integral e igualitário a medicamentos e informação, como para defender a limitação a esse acesso.

Dados apresentados durante a audiência demonstram a relevância do tema. Aproximadamente $70 \%$ da população brasileira depende exclusivamente do SUS para ter acesso a serviços e produtos de saúde(3).

O Ministério da Saúde despendeu à Assistência Farmacêutica 13,1\% ( $R \$ 5.866 .196 .247,00$ ) de todo seu orçamento em 2008 (em 2002 foram 5,8\%) e é responsável por $80 \%$ dos recursos necessários pactuados para atender a demanda de medicamentos dos três programas do componente ${ }^{(4)}$.

Estudos exploratórios entre 2005 e 2007, em alguns estados, mostram que parcela significativa de medicamentos fornecidos judicialmente através do SUS, e cujos fármacos não pertencem a listas oficiais, (1) não se baseia em evidências científicas ou (2) há substituto terapêutico(5),(6).

No Rio Grande do Sul, o número de ações judiciais contra os poderes executivos estadual e municipais para fornecimento de medicamentos, em 2008, aumentou $16 \%$ em relação a $2007^{(7)}$.

(1) GONÇALVES, Janaína Barbier. Transcrição de palestra proferida na audiência pública da saúde. Supremo Tribunal Federal, 4 de maio de 2009. Disponível em: <http://www.stf.jus.br/arquivo/cms/ processoAudienciaPublicaSaude/anexo/PGERS.pdf>. Acesso em: 15 jan. 2013.

(2) TERRA, Osmar Gasparini. Transcrição de palestra proferida na audiência pública da saúde. Supremo Tribunal Federal, 29 de abril de 2009. Disponível em: <http://www.stf.jus.br/arquivo/cms/ processoAudienciaPublicaSaude/anexo/Sr_Osmar_Terra.pdf>. Acesso em: 15 jan. 2013.

(3) GUIMARÃES, Reinaldo Felipe Nery. Transcrição de palestra proferida na audiência pública da saúde. Supremo Tribunal Federal, 07 de maio de 2009. Disponível em: <http://www.stf.jus.br/arquivo/ cms/processoAudienciaPublicaSaude/anexo/Reinaldo.pdf>. Acesso em: 15 jan. 2013.

(4) GONÇALVES, Janaína Barbier. op. cit.

(5) VIEIRA, Fabíola Sulpino; ZUCCHI, Paola. Distorções causadas pelas ações judiciais à política de medicamentos no Brasil. Revista de Saúde Pública, São Paulo, v. 41, n. 2, p. 214-222, 2007.

(6) LOPES, L.C.; BARBERATO Filho, S.; POLIMENO N.C.; COSTA, A.C.; NAFFAH, Filho M.; CORREA, M.C.; OSORIO-DE-CASTRO, C.G.S. Medicamentos antineoplásicos e ações judiciais: contribuição para o modelo de assistência farmacêutica no SUS. In: SEMINÁRIO DE AVALIAÇÃO Programa de Pesquisa para o Sistema Único de Saúde - PPSUS/SP 2006-2007: rumo à incorporação dos resultados das pesquisas no âmbito do SUS/SP. São Paulo; 2010. Disponível em: <http:// portal.saude.sp.gov.br/resources/instituto-de-saude/ppsus/relatorios-is/seminarios-de-avaliacao-eacompanhamento-ppsus-sp/seminario_de_avaliacao_e_acompanhamento_ppsus-sp_2006-2007. pdf>. Acesso em: 19 fev. 2013.

(7) GONÇALVES, Janaína Barbier. op. cit. 
Dentre as alternativas apresentadas durante a audiência no STF para diminuir o fenômeno da judicialização da saúde, citam-se a criação de centros de referência regionais ${ }^{(8)}$ para aplicação de critérios da medicina baseada em evidências ${ }^{(9),(10)}$, e o uso de critérios de segurança, eficácia, efetividade e custo-efetividade para incorporação de medicamentos no rol de produtos remunerados pelo SUS, através da metodologia da Avaliação de Tecnologias em Saúde ${ }^{(11)}$.

Dessa audiência, o Conselho Nacional de Justiça (CNJ) orientou às instâncias do Poder Judiciário a adotar medidas visando melhor subsidiar os magistrados e operadores do direito, para assegurar maior eficiência na solução das demandas envolvendo a assistência à saúde, principalmente em medicamentos $^{(12)}$. O CNJ também instituiu o Fórum Nacional para monitorar e resolver demandas de assistência à saúde, elaborar estudos, propor medidas para o aperfeiçoamento e efetividade de procedimentos e prevenir novos conflitos ${ }^{(13)}$.

Os discursos durante a audiência pareceram demonstrar que (1) o usuário não possui garantia do direito pleno ao acesso e ao Uso Racional de Medicamentos (URM), no SUS, para atendimento de suas necessidades especiais $^{(14)}$; (2) as ações de Assistência Farmacêutica no SUS tendem a

(8) Constituídos por médicos vindos da academia e de hospitais, por farmacêuticos vindos da esfera estadual e representantes do Judiciário; no entanto, Picón não menciona parcerias com Centros de Informações sobre Medicamentos. PICON, Paulo Dornelles. Transcrição de palestra proferida na audiência pública da saúde. Supremo Tribunal Federal, 4 maio de 2009. Disponível em: <http://www.stf. jus.br/arquivo/cms/processoAudienciaPublicaSaude/anexo/Paulo_Picon.pdfs. Acesso em: 15 jan. 2013.

(9) Aplicação do método científico a toda a prática médica, ligada a tradições médicas estabelecidas ou àquelas que ainda não foram submetidas à sistematização científica. "Evidências" significam provas científicas buscadas na crítica da literatura, consulta da literatura original (fontes primárias) e/ou revisões sistemáticas da literatura e diretrizes clínicas baseadas em evidências [KEINERT, Tânia Margarete Mezzomo; PAULA, Sílvia Helena Bastos de; BONFIM, José Rubem de Alcântara (Orgs.). Ações judiciais no SUS e a promoção do direito à saúde. São Paulo: Instituto de Saúde, 2009. p. 16. Disponível em: <http://www.google.com.br/url?sa=t\&rct=j\&q=www.hgf.ce.gov. br\%2F...\%2F25-versao-eletronica-do-livro-qas-acoes-judici...\&source=web\&cd=2\&ved=0CDMQF jAB\&url=http\%3A\%2F\%2Fwww.hgf.ce.gov.br\%2Findex.php\%2Fdownloads\%2Fcategory\%2F25versao-eletronica-do-livro-qas-acoes-judiciais-no-sus-e-a-promocao-do-direito-a-saudeq\%3Fdownload\%3D18\%253Aversao-eletronica-do-livro-qas-acoes-judiciais-no-sus-e-a-promocaodo-direito-a-saudeq-\&ei=CH31UKKOJJKm9gSDxIHIDQ\&usg=AFQjCNEj3WSusXAmJIB9huEcolxN6 LcNAg\&bvm=bv.41018144,d.eWU>. Acesso em: 15 jan. 2013].

(10) PICON, Paulo Dornelles. op. cit.

(11) GUIMARÃES, Reinaldo Felipe Nery. op. cit.

(12) CONSELHO NACIONAL DE JUSTIÇA. Recomendação $n^{\circ}$ 31, de 30 de março de 2010. "Recomenda aos Tribunais a adoção de medidas visando melhor subsidiar os magistrados e operadores do direito, para assegurar maior eficiência na solução das demandas judiciais envolvendo a assistência à saúde". Disponível em: <http://www.cnj.jus.br/atos-normativos?documento=877> . Acesso em: 15 jan. 2013.

(13) CONSELHO NACIONAL DE JUSTIÇA. Resolução n 107, de 6 de abril de 2010. "Institui o Fórum Nacional do Judiciário para monitoramento e resolução das demandas de assistência à saúde". Disponível em: <http://www.cnj.jus.br/atos-normativos?documento=173>. Acesso em: 15 jan. 2013.

(14) Como produtos sem corantes ou sem lactose, ou de dose específica que requeira manipulação ou derivação de preparação. 
privilegiar o acesso e o uso racional de medicamentos ${ }^{(15)}$ preconizados pela medicina convencional dominante ${ }^{(16)}$, embora haja iniciativas públicas para acesso a outras práticas terapêuticas ${ }^{(17),(18)}$; (3) o usuário não tem direito, conforme aduz Pascalicchio ${ }^{(19)}$, à opção de tratamento medicamentoso, a partir de uma medicina menos convencional e mais holística ou alternativa ${ }^{(20)}$ reconhecida oficialmente, cujas evidências científicas possuem racionalidade própria; (4) a existência de CIMs, pode contribuir para que os atores da saúde ou do direito elaborem juízo de valor sobre o acesso e o uso racional de medicamentos no SUS.

O direito à saúde é um direito constitucional(21) e abarca a assistência terapêutica e farmacêutica integral e universal, com equidade ${ }^{(22)}$. As ações de AF no SUS decorrem da Política Nacional de Assistência Farmacêutica e estão

(15) O paciente deve receber o medicamento apropriado para suas necessidades clínicas, nas doses individualmente requeridas para um adequado período de tempo e a um baixo custo ao paciente e sua comunidade. [ORGANIZAÇÃO PAN-AMERICANA DA SAÚDE. Uso racional de medicamentos y otras tecnologías de salud. Disponível em: < http://new.paho.org/hq/index.php?option=com_content\& view $=$ category \&layout=blog\&id=1268\&ltemid=1180>. Acesso em: 15 jan. 2013]

(16) O termo "medicina convencional dominante" foi utilizado para demonstrar que a Assistência Farmacêutica oficial evidencia informação, custeio e práticas relacionadas a medicamentos utilizados pela cultura médica predominante no país, ou seja, medicina alopática [MINISTÉRIO DA SAÚDE. Profissional e Gestor/Medicamentos. Disponível em: <http://portal.saude.gov.br/portal/saude/ profissional/area.cfm?id_area=1000>. Acesso em: 18 fev. 2013].

(17) MINISTÉRIO DA SAÚDE. Secretaria de Atenção à Saúde. Departamento de Atenção Básica. Política Nacional de Práticas Integrativas e Complementares no SUS. 1. ed. Brasília: Ministério da Saúde, 2008. Disponível em: <http://bvsms.saude.gov.br/bvs/publicacoes/pnpic_atitude_ampliacao_ acesso.pdf $>$. Acesso em: 15 jan. 2013.

(18) MINISTÉRIO DA SAÚDE. Secretaria de Ciência, Tecnologia e Insumos Estratégicos. Departamento de Assistência Farmacêutica. Política Nacional de Plantas Medicinais e Fitoterápicos. Brasília: Ministério da Saúde, 2006. (Série B. Textos Básicos de Saúde). Disponível em: <http:// bvsms.saude.gov.br/bvs/publicacoes/politica_nacional_fitoterapicos.pdf>. Acesso em: 15 jan. 2013.

(19) PASCALICCHIO, Áurea Eleutério. A necessidade de uma medicina holística. In: BONFIM, José Ruben de Alcântara; MERCUCCI, Vera Lúcia (Orgs.). A construção da política de medicamentos. São Paulo: Hucitec; SOBRAVIME, 1997. p. 219-221.

(20) Práticas menos convencionais e mais holísticas ou alternativas se relacionam (1) com sistemas médicos complexos (abordagens do campo das práticas integrativas complementares que possuem teorias próprias sobre o processo saúde/doença, diagnóstico e terapêutica [LUZ. T. M apud MINISTÉRIO DA SAÚDE. Secretaria de Atenção à Saúde. Departamento de Atenção Básica. Política Nacional de Práticas Integrativas e Complementares no SUS, cit., p. 11]), como a medicina homeopática, a medicina antroposófica, medicina tradicional chinesa/ acupuntura, termalismo social/crenoterapia e fitoterapia; (2) com os recursos terapêuticos (instrumentos utilizados nos diferentes sistemas médicos complexos). (MINISTÉRIO DA SAÚDE. Secretaria de Atenção à Saúde. Departamento de Atenção Básica. Política Nacional de Práticas Integrativas e Complementares no SUS, cit.); (3) e práticas populares e tradicionais, como as plantas medicinais (MINISTÉRIO DA SAÚDE. Secretaria de Ciência, Tecnologia e Insumos Estratégicos. Departamento de Assistência Farmacêutica. Política Nacional de Plantas Medicinais e Fitoterápicos, cit.).

(21) Art. $6^{\circ}$. BRASIL. Constituição da República Federativa do Brasil de 1988. Disponível em: <http:// www.planalto.gov.br/ccivil_03/constituicao/ConstituicaoCompilado.htm>. Acesso em: 15 jan. 2013.

(22) BRASIL. Lei Federal $n^{\circ} 8.080$, de 19 de setembro de 1990. "Dispõe sobre as condições para a promoção, proteção e recuperação da saúde, a organização e o funcionamento dos serviços correspondentes e dá outras providências". Disponível em: <http://www.planalto.gov.br/ccivil_03/leis/ L8080.htm>. Acesso em: 15 jan. 2013. 
voltadas à promoção, proteção e recuperação da saúde, por meio da promoção do acesso e uso racional dos medicamentos ${ }^{(23)}$.

Os CIMs, com suas estruturas e organização diversas, fornecem informação criticamente avaliada e auxiliam profissionais de saúde à tomada de decisão sobre o acesso e o uso racional de medicamentos ${ }^{(24)}$, e podem ajudar aos demais atores da saúde e do direito. Por isso, a inserção desses serviços especializados nas políticas públicas de saúde pode ser estratégia útil ao direito sanitário e contribuir com a universalidade e integralidade no acesso e URM no SUS.

Até o momento, no Brasil, as autoridades sanitárias pouco aproveitaram os CIMs, embora sejam considerados ferramentas úteis à promoção do uso racional de medicamentos e à diminuição das assimetrias de informação técnica na $A^{(25)}$ e sejam utilizados por profissionais da rede. Em estudo realizado no Rio Grande do Sul, 31\% das solicitações de informação recebidas por um CIM em 2007 provieram de profissionais atuantes em serviços de saúde vinculados ao SUS, das quais $30,2 \%$ eram originárias de farmácias de prefeituras municipais ${ }^{(26)}$.

O presente trabalho dialoga com a ampla temática das políticas públicas de saúde formuladas após a Constituição Federal de 1988, mais especificamente as políticas farmacêuticas ou políticas e programas de saúde com escopo no medicamento; está em sintonia com o princípio da integralidade de assistência farmacêutica do SUS, pois insere-se no contexto do uso racional de medicamentos; relaciona as políticas públicas sobre AF com o direito sanitário; insere-se nos princípios do direito sanitário em relação à universalidade, integralidade e equidade das ações em saúde, uma vez que a garantia desses princípios requer ações de preservação do direito à opção terapêutica e medicamentosa e do direito dos profissionais de saúde ao acesso à informação técnica necessária e suficiente para viabilizar essa garantia.

Para verificar se os CIMs podem contribuir como estratégia nas ações da Assistência Farmacêutica no SUS para o acesso e uso racional de medicamentos pela população, foram analisadas: as políticas públicas de saúde; a via de acesso e aspectos sobre uso racional de medicamentos preconizado nas políticas públicas de saúde vigentes; a importância do acesso à informação sobre medicamentos para contribuição ao uso racional de medicamentos no SUS. Em seguida, este artigo propõe ações para que os CIMs contribuam como estratégia para qualificar o acesso, o uso racional e a dispensação de produtos e serviços no SUS.

(23) MINISTÉRIO DA SAÚDE. Profissional e Gestor/Medicamentos, cit.

(24) FISCHER, Maria Isabel et. al. CIM-RS: o desafio de qualificar a informação. Porto Alegre: Ed. da UFRGS, 2007.

(25) MOTA, Daniel Marques et al. Uso racional de medicamentos: uma abordagem econômica para tomada de decisões. Ciência \& Saúde Coletiva, Rio de Janeiro, v. 13, supl. 0, abr. 2008. Disponível em: <http://www.scielosp.org/scielo.php?script=sci_arttext\&pid=S1413-81232008000700008\&lng=pt \&nrm=iso >. Acesso em: 15 jan. 2013. http://dx.doi.org/10.1590/S1413-81232008000700008.

(26) FORMIGUIERI, Ramon Vinícius. Caracterização dos estabelecimentos de origem das solicitações de informação CIM-RS-2007. 2008. Trabalho apresentado no Salão de Extensão Universitária da UFRGS, Porto Alegre, 2008. Disponível em: <http://www.ufrgs.br/boletimcimrs/ SUS\%20EXTENSAO\%20-\%20Ramon\%202008.pdf>. Acesso em: 15 jan. 2013. 


\section{METODOLOGIA}

Foi realizada seleção de fontes sobre direito sanitário, planejamento estratégico em saúde, políticas públicas de saúde, assistência farmacêutica e centros de informação sobre medicamentos; revisão em fontes bibliográficas e eletrônicas sobre o tema informação sobre medicamentos no âmbito das políticas farmacêuticas e do direito sanitário, através de consulta a banco de dados do Supremo Tribunal Federal, Superior Tribunal de Justiça, Ministério da Saúde, Conselho Nacional de Saúde, Conselho Federal de Farmácia; e consulta às bases de dados Scielo e Biblioteca Virtual de Saúde, usando os descritores (isolados ou combinados): uso racional de medicamento(s), decisões judiciais, medicamento, centro, informação(ões), SUS, política(s), pública(s), judicialização, sem limite de busca, para localização de artigos relacionados com os itens anteriores.

Foi realizada pesquisa em documentos versando sobre políticas públicas de saúde relacionadas ao medicamento, cujo conteúdo foi avaliado criticamente quanto aos objetivos da pesquisa à luz do direito sanitário.

A discussão foi voltada para sujeitos que atuam ou necessitam de serviços da atenção básica do SUS - via de entrada preferencial do sistema de saúde ${ }^{(27),(28),(29)}$ - e procurou contemplar práticas terapêuticas medicamentosas preconizadas na Assistência Farmacêutica.

\section{DISCUSSÃO}

A situação apresentada insere-se na visão proposta por Dallari(30) sobre direito à saúde - como reivindicação de um direito humano - e do direito à saúde pública - como conjunto de normas jurídicas para promoção, prevenção e recuperação da saúde de todos os indivíduos que compõem o povo de determinado Estado.

(27) MINISTÉRIO DA SAÚDE. Entendendo o SUS. Ministério da Saúde, 2006. Disponível em: $<$ http://portal.saude.gov.br/portal/arquivos/pdf/cartilha_entendendo_o_sus_2007.pdf>. Acesso em: 15 jan. 2013.

(28) BRASIL. Lei Federal $n^{\circ} 12.401$, de 28 de abril de 2011. "Altera a Lei $n^{\circ} 8.080$, de 19 de setembro de 1990, para dispor sobre a assistência terapêutica e a incorporação de tecnologia em saúde no âmbito do Sistema Único de Saúde." Disponível em: <http://www.planalto.gov.br/ccivil_03/_Ato20112014/2011/Lei/L12401.htm>. Acesso em: 15 jan. 2013.

(29) BRASIL. Decreto Federal $n^{\circ} 7.508$, de 28 de junho de 2011. "Regulamenta a Lei $n^{\circ} 8.080$, de 19 de setembro de 1990, para dispor sobre a organização do Sistema Único de Saúde - SUS, o planejamento da saúde, a assistência à saúde e a articulação interfederativa, e dá outras". Disponível em: <http://www. planalto.gov.br/ccivil_03/_ato2011-2014/2011/decreto/D7508.htm>. Acesso em: 15 jan. 2013.

(30) AITH, Fernando Mussa Abujamra. Consolidação do direito sanitário no Brasil. In: COSTA, Alexandre Bernardino et al (Orgs.). O Direito achado na rua: introdução crítica ao direito à saúde. Brasília: CEAD/UnB, 2008. p. 65-75. 
O direito sanitário constituiu-se devido ao seu sentido social, pois contribui com a sociedade "para uma correta organização das ações e serviços de saúde nela existentes, visando sempre ao desenvolvimento da sociedade e à defesa dos valores juridicamente protegidos por essa mesma sociedade"(31).

A construção desse sentido social através do direito sanitário possui garantia constitucional, pois a saúde é direito de todos e dever do Estado, "garantido mediante políticas sociais e econômicas que visem à redução do risco de doença e de outros agravos e ao acesso universal e igualitário às ações e serviços para sua promoção, proteção e recuperação"(32).

A Constituição Federal de 1988 organizou esse contexto através do SUS, sendo um dos principais avanços em relação ao desenvolvimento de políticas públicas do Estado de caráter universalista ${ }^{(33)}$. Dentre seu campo de atuação destaca-se a assistência terapêutica integral, inclusive farmacêutica, a qualquer pessoa através de ações de promoção, proteção e recuperação da saúde, com a integração das ações assistenciais e das atividades preventivas ${ }^{(34)}$.

No entanto, a garantia do direito à saúde até as últimas instâncias depende que esse direito possua o mesmo significado para os diferentes atores no sistema. Por isso, esse significado deve ser permanentemente construído na sociedade, pois ele é uma demanda que apenas pode ser encontrada pelas próprias pessoas da comunidade interessada ${ }^{(35)}$.

Assim sendo, o direito sanitário, ou direito à saúde, pode ser e necessita ser extensivo a qualquer indivíduo, como controle social, usuário, profissional de saúde e gestor no sistema, e operador do direito.

A saúde é um tema complexo, cujo conceito é o resultado de um conjunto amplo de determinantes analisados a partir de uma visão sistêmica e ampliada ${ }^{(36)}$. O direito sanitário comporta um contexto regulatório e outro administrativo (ou de gestão dos serviços e do sistema de saúde), e regulamenta a própria relação entre indivíduos e estes com os profissionais de saúde ${ }^{(37)}$.

(31) AITH, Fernando Mussa Abujamra. op. cit., p. 74.

(32) Art. 196. BRASIL. Constituição da República Federativa do Brasil de 1988. Disponível em: <http:/l www.planalto.gov.br/ccivil_03/constituicao/constituicaocompilado.htm>. Acesso em: 15 jan. 2013.

(33) MACHADO, Felipe Rangel de Souza. Contribuições ao debate da judicialização da saúde no Brasil. Revista de Direito Sanitário, São Paulo, v. 9, n. 2, p. 73-91, jul./out. 2008.

(34) BRASIL. Lei Federal $n^{\circ}$ 8.080. Disponível em: <http://www.planalto.gov.br/ccivil_03/Leis/L8080. htm>. Acesso em: 15 jan. 2013.

(35) DALLARI, Sueli Gandolfi. O conteúdo do direito à saúde. In: COSTA, Alexandre Bernardino et al (Orgs.). op. cit., p. 91-101.

(36) DELDUQUE, Maria Célia; OLIVEIRA, Mariana S. de Carvalho. Tijolo por tijolo: a construção permanente do direito à saúde. In: COSTA, Alexandre Bernardino et al (Orgs.). op. cit., p. 103-111.

(37) KEINERT, Tânia Margarete Mezzomo; PAULA, Sílvia Helena Bastos de; BONFIM, José Rubem de Alcântara (Orgs.). op. cit., p. 16. 
O principal executor do direito à saúde é o Poder Executivo, cabendo-Ihe articular com os mais diversos parceiros, dentro e fora do poder público, para que esse direito seja fruto das verdadeiras necessidades da sociedade ${ }^{(38)}$.

A compreensão do SUS como um processo em construção que demanda enormes esforços do Estado e das forças da sociedade civil exige (1) a necessidade de articulação coerente dos diversos atores sociais envolvidos com as políticas sociais em saúde e (2) obtenção de respostas afirmativas, inclusivas e solidárias para os desafios da saúde do ponto de vista do exercício dos direitos civis, da cidadania e do controle social(39).

O usuário possui direito à terapia medicamentosa no SUS se cumulativamente estiver assistido por ações e serviços de saúde do sistema, se o medicamento tiver sido prescrito por profissional de saúde no exercício regular de suas funções no SUS, se a prescrição estiver em conformidade com a Relação Nacional de Medicamentos Essenciais (Rename) ${ }^{(40)}$ e com os Protocolos Clínicos e Diretrizes Terapêuticas ou, na sua falta, com lista específica complementar estadual, distrital ou municipal de medicamentos e se a dispensação tiver ocorrido em unidades indicadas pela direção do SUS ${ }^{(41)}$. Ou seja, o direito à saúde universal e integral somente ocorrerá se o sistema enxergar esse sujeito - para tanto, deverá estar formalmente inserido no SUS; mas essa inserção exige potencial limitação ao acesso a práticas terapêuticas e medicamentosas, pois o usuário ficará restrito às terapias e práticas disponíveis localmente.

Apesar dos esforços de gestão, o SUS depara-se diante de uma contradição: embora saúde seja um direito universal, o SUS não consegue assegurá-lo na prática. Diante desse dilema, grupos da sociedade têm buscado a garantia de seus direitos constitucionais junto às instâncias judiciais ${ }^{(42)}$.

A concessão de liminares para a aquisição imediata de medicamentos pelo gestor público, em geral em processo sumário e sem licitação, intervém diretamente na gestão do orçamento aprovado pelo Poder Legislativo e na condução das políticas públicas de saúde estabelecida pelo Executivo ${ }^{(43)}$.

No entanto, a judicialização da saúde pode ser benéfica para ampliação das ações e serviços oferecidos pelo Estado, dentre os quais medicamentos, e

(38) DELDUQUE, Maria Célia; OLIVEIRA, Mariana S. de Carvalho. op. cit.

(39) DÍAZ BERMÚDEZ, Ximena Pamela et al. O Sistema Único de saúde, uma retrospectiva e principais desafios. In: COSTA, Alexandre Bernardino et al (Orgs.). op. cit., p. 113-126

(40) Conjunto dos produtos considerados básicos e indispensáveis para atender a maioria dos problemas de saúde da população, os quais devem estar continuamente disponíveis aos segmentos da sociedade que deles necessitem, nas formas farmacêuticas apropriadas. MINISTÉRIO DA SAÚDE. Secretaria de Políticas de Saúde. Departamento de Atenção Básica. Política Nacional de Medicamentos. Brasília: Ministério da Saúde, 2001. [Série C. Projetos, Programas e Relatórios, n. 25]. Disponível em: <pdf http:// bvsms.saude.gov.br/bvs/publicacoes/politica_medicamentos.pdf $>$. Acesso em: 15 jan. 2013. p 12.

(41) BRASIL. Decreto Federal $n^{\circ} 7.508$, de 28 de junho de 2011. op.cit.

(42) MACHADO, Felipe Rangel de Souza. op. cit.

(43) Id. Ibid. 
para a própria revisão das políticas vigentes ${ }^{(44)}$, pois o aumento crescente dessas demandas judiciais pode indicar falhas de gestão em relação aos princípios da integralidade e universalidade terapêutica e medicamentosa preconizadas pelas políticas públicas de saúde.

A complexidade desse atendimento perante os princípios constitucionais remonta às propostas aprovadas na $8^{a}$ Conferência Nacional de Saúde ${ }^{(45)}$, as quais valorizaram a abordagem humanizada sugerida na Conferência Internacional sobre Atenção Primária em Saúde, realizada em Alma-Ata em 1978, e no Programa de Medicina Tradicional criado pela Organização Mundial da Saúde (OMS) na década de $1970^{(46)}$.

A discussão sobre políticas públicas de saúde em fóruns de deliberação do controle social do SUS possibilitou que representações de atores diversos pautassem problemas e propusessem soluções relacionadas a questões sobre qualidade, uso irracional e dificuldade de acesso a medicamentos ${ }^{(47)}$.

Dessa discussão, adveio a necessidade de formulação e implementação de políticas públicas em saúde ${ }^{(48)}$, abarcando medicamentos.

Seleção, disponibilidade, acesso, educação, informação e comunicação foram elementos considerados componentes da Assistência Farmacêutica e necessários para uma política de medicamentos, através da elaboração de estratégias - como centros de informação - (1) para fornecimento de informação objetiva, atualizada e imparcial aos profissionais e (2) para a garantia de acesso ao público em geral de informação relevante sobre medicamentos ${ }^{(49)}$.

Nesse cenário, o Ministério da Saúde instituiu a Política Nacional de Medicamentos em 1998, de cujas diretrizes e prioridades citam-se ${ }^{(50)}$ :

- a organização da Rename;

- a reorientação da Assistência Farmacêutica, através de ações nas três esferas do SUS para promoção do acesso da população aos medicamentos essenciais;

(44) MACHADO, Felipe Rangel de Souza. op. cit.

(45) CONSELHO NACIONAL DE SAÚDE. $8^{a}$. Conferência Nacional de Saúde. Relatório final. Brasília, 17 a 21 de Março de 1986. Brasília: Ministério da Saúde / Ministério da Previdência e Assistência Social. Disponível em: <http://conselho.saude.gov.br/biblioteca/Relatorios/relatorio_8.pdf>. Acesso em: 15 jan. 2013.

(46) MINISTÉRIO DA SAÚDE. Secretaria de Ciência, Tecnologia e Insumos Estratégicos. Departamento de Assistência Farmacêutica. Política Nacional de Plantas Medicinais e Fitoterápicos, cit.

(47) CZERMAINSKI, Sílvia Beatriz Costa. A política nacional de plantas medicinais e fitoterápicos: um estudo a partir da análise de políticas públicas. 2009. 82 f. Dissertação (Mestrado em Ciências Farmacêuticas) - Universidade Federal do Rio Grande do Sul, Porto Alegre, 2009.

(48) BONFIM, José Ruben de Alcântara; MERCUCCI, Vera Lúcia (Orgs.). op. cit.

(49) JONCHEERE, Kees de. A necessidade e os elementos de uma política nacional de medicamentos. In: BONFIM, José Ruben de Alcântara; MERCUCCI, Vera Lúcia (Orgs.). op. cit., p. 49-63.

(50) MINISTÉRIO DA SAÚDE. Secretaria de Políticas de Saúde. Departamento de Atenção Básica. Política Nacional de Medicamentos, cit. 
- a promoção do URM por meio de de campanhas educativas ${ }^{(51)}$ com participação das entidades representativas dos profissionais de saúde; elaboração de Formulário Terapêutico Nacional (FTN) para a orientação da prescrição e dispensação; estimulação do acesso do profissional a conhecimentos e treinamentos relacionados à gestão de sistemas de saúde e de informação e guias terapêuticos padronizados; e disseminação de informações objetivas e atualizadas para garantia do URM.

A Política Nacional de Medicamentos inovou ao estabelecer diretrizes, prioridades e responsabilidades de gestão aos três níveis de administração da AF e ao parametrizar a promoção do uso racional de medicamentos na população, prescritores e dispensadores.

Mas, essa política pública sugere limitar a universalidade e a integralidade constitucional do direito à saúde, pois apenas garante o direito à população que demanda por medicamentos (em vez da que deles necessita); contempla somente a terapia reconhecida para tratamento com medicamentos essenciais; e não incluiu formalmente os CIMs, embora informação técnico-científica sobre medicamento fosse diretriz transversal entre Rename, Assistência Farmacêutica e URM, inerente à própria aplicabilidade dessa política pública de saúde nas três esferas de gestão do SUS.

Os pontos fracos dessas limitações podem estar na gestão, seguindo entendimento de Testa ${ }^{(52)}$, como o favorecimento da institucionalização de um modelo de política pública baseada em um padrão econômico-acadêmico dominante à época de uma medicina convencional de causa-efeito, conservadora e fragmentada, em detrimento de práticas alternativas e tradicionais de assistência à saúde, mais humanizadas.

Eventos ocorridos no final da década de $1990^{(53)}$ somados com a força das conferências de saúde possibilitaram a realização da I Conferência Nacional de Medicamentos e Assistência Farmacêutica em $2003^{(54)}$, a qual reforçou a necessidade de estimular a implantação e utilização de centros de informação sobre medicamentos com financiamento público nos estados e municípios e de estimular outras atividades para promoção do acesso e URM(55).

(51) Sobre riscos da automedicação, da interrupção do tratamento, da troca da medicação prescrita, da necessidade da receita médica para dispensação de medicamentos tarjados. MINISTÉRIO DA SAÚDE. Secretaria de Políticas de Saúde. Departamento de Atenção Básica. Política Nacional de Medicamentos, cit., p. 16.

(52) TESTA, Mário. Pensamento estratégico e lógica de programação: o caso da saúde. São Paulo: Hucitec; Rio de Janeiro: ABRASCO, 1995.

(53) Extinção da Central de Medicamentos (CEME), denúncias de medicamentos falsificados, CPI dos Medicamentos na Câmara Federal, criação da PNM, edição da primeira portaria de financiamento da Assistência Farmacêutica Básica, Lei dos Genéricos, dentre outros.

(54) CZERMAINSKI, Sílvia Beatriz Costa. op. cit.

(55) CONSELHO NACIONAL DE SAÚDE. $1^{\text {a }}$. CONFERÊNCIA NACIONAL DE MEDICAMENTOS E ASSISTÊNCIA FARMACÊUTICA. Relatório final. Brasília: Ministério da Saúde, 2005. Série D. Reuniões e Conferências. Disponível em: <http://conselho.saude.gov.br/biblioteca/Relatorios/confer_ nacional_de\%20medicamentos.pdf >. Acesso em: 15 jan. 2013. 
A demonstração de forças sobre a problemática do medicamento e da assistência farmacêutica contribuiu para a construção de um novo enfoque no SUS, o qual foi incorporado na Política Nacional de Assistência Farmacêutica (PNAF) em 2004(56).

Dentre os eixos estratégicos da PNAF, a garantia de acesso e equidade às ações de saúde inclui necessariamente a Assistência Farmacêutica, a utilização da Rename e a pactuação de ações interssetoriais para internalização e desenvolvimento de tecnologias que atendam às necessidades de produtos e serviços do SUS, nos diferentes níveis de atenção( ${ }^{(57)}$.

O conjunto de ações da Assistência Farmacêutica envolve o ciclo da AF - seleção, programação, aquisição, distribuição, gestão de materiais, dispensação( ${ }^{(58)}$-, a pesquisa, o desenvolvimento e a produção, garantia da qualidade dos produtos e serviços, acompanhamento e avaliação de utilização de medicamentos e insumos; e envolve aquelas referentes à Atenção Farmacêutica( ${ }^{(59)}$. Essa interação também deve incluir as concepções dos seus sujeitos, respeitadas as suas especificidades biopsicossociais, sob a ótica da integralidade das ações de saúde ${ }^{(60)}$.

A Assistência Farmacêutica tem o medicamento como insumo essencial, visa ao acesso e ao seu uso racional e deve ser compreendida como política pública norteadora para a formulação de políticas setoriais, principalmente as políticas de medicamentos, dentre outras ${ }^{(61)}$, podendo-se afirmar que a PNAF é essencial para implementar a Política Nacional de Medicamentos.

A PNAF inova ao incluir a Atenção Farmacêutica como condição à humanização das ações; ampliar a atuação da AF, pois reconhece sua concepção integral; integrar a AF ao sistema de saúde para agregar valor às ações e aos serviços de saúde; e ampliar a compreensão de URM, possibilitando a crítica de produtos, tecnologias e serviços destinados à saúde.

(56) CZERMAINSKI, Sílvia Beatriz Costa. op. cit.

(57) CONSELHO NACIONAL DE SAÚDE. Resolução $n^{\circ} 338$, de 6 de maio de 2004. "Aprova a Política Nacional de Assistência Farmacêutica". Disponível em: <http://www.conselho.saude.gov.br/ resolucoes/reso_04.htm>. Acesso em: 15 jan. 2013.

(58) MINISTÉRIO DA SAÚDE. Secretaria de Ciência, Tecnologia e Insumos Estratégicos. Departamento de Assistência Farmacêutica e Insumos Estratégicos. Assistência farmacêutica na atenção básica: instruções técnicas para sua organização. 2. ed. Brasília: Ministério da Saúde, 2006. Série A. Normas e Manuais Técnicos. Disponível em: <http://www.ensp.fiocruz.br/portal-ensp/ judicializacao/pdfs/283.pdf>. Acesso em: 15 jan. 2013.

(59) Modelo de prática farmacêutica desenvolvido no contexto da AF que compreende atitudes, valores éticos, comportamentos, habilidades, compromissos e corresponsabilidades na prevenção de doenças, promoção e recuperação da saúde, de forma integrada à equipe de saúde; é a interação direta do farmacêutico com o usuário, visando uma farmacoterapia racional e a obtenção de resultados definidos e mensuráveis voltados para a melhoria da qualidade de vida (CONSELHO NACIONAL DE SAÚDE. Resolução $n^{\circ} 338$, de 6 de maio de 2004. op.cit.

(60) CONSELHO NACIONAL DE SAÚDE. Resolução $n^{\circ}$ 338, de 6 de maio de 2004. op. cit.

(61) Id. Ibid. 
Para os eixos estratégicos da PNAF à Atenção Básica ${ }^{(62)}$, a informação sobre medicamentos produzida pode ser considerada inerente e estratégica para o desenvolvimento da AF e dos recursos humanos e serviços, além de possibilitar o resultado da própria política.

Discussões temáticas sobre SUS, Assistência Farmacêutica e garantia da universalidade, integralidade e equidade nos serviços de saúde influenciaram as organizações de saúde e os perfis profissionais exigidos, propiciando propostas e necessidades de novas práticas na AF para contemplar o direito de acesso ao URM e à opção terapêutica, enfaticamente colocada nas conferências de saúde e nas recomendações e reivindicações pela inserção de terapias tradicionais no SUS ${ }^{(63)}$.

Nesse contexto, em 2006, é aprovada a Política Nacional de Práticas Integrativas e Complementares no SUS (Pnpic) ${ }^{(64)}$ e a Política Nacional de Plantas Medicinais e Fitoterápicos (Pnpmf) ${ }^{(65)}$.

A Pnpic contribuiu para o fortalecimento dos princípios fundamentais do SUS, incorporando e implementando experiências desenvolvidas na rede pública de muitos municípios e estados. Essas práticas legitimadas pela sociedade nos campos da prevenção de agravos e da promoção, manutenção e recuperação da saúde basearam-se em modelo de atenção humanizada e centrada na integralidade do indivíduo, contemplando sistemas médicos complexos e recursos terapêuticos, chamados pela OMS de medicina tradicional e complementar/ alternativa (integrativa) ${ }^{(66)}$.

Diretrizes inovadoras como divulgação e informação dos conhecimentos sobre práticas integrativas e complementares ${ }^{(67)}$ para profissionais de saúde, gestores e usuários, no âmbito da Estratégia Saúde da Família (ESF) e Programa de Agentes Comunitários de Saúde, e o provimento do acesso a medicamentos homeopáticos e fitoterápicos, assegurando as especificidades da assistência farmacêutica, contribuíram para ampliar o conceito de URM, estendendo-o às plantas medicinais e fitoterápicos ${ }^{(68)}$; mas pareceram limitar o acesso a tais práticas somente aos atores contemplados pela ESF e por práticas acessíveis localmente.

(62) MINISTÉRIO DA SAÚDE. Secretaria de Ciência, Tecnologia e Insumos Estratégicos. Departamento de Assistência Farmacêutica e Insumos Estratégicos. Assistência farmacêutica na atenção básica: instruções técnicas para sua organização, cit.

(63) CZERMAINSKI, Sílvia Beatriz Costa. op. cit.

(64) MINISTÉRIO DA SAÚDE. Secretaria de Atenção à Saúde. Departamento de Atenção Básica. Política Nacional de Práticas Integrativas e Compleentares no SUS, cit.

(65) MINISTÉRIO DA SAÚDE. Secretaria de Ciência, Tecnologia e Insumos Estratégicos. Departamento de Assistência Farmacêutica. Política Nacional de Plantas Medicinais e Fitoterápicos, cit.

(66) MINISTÉRIO DA SAÚDE. Secretaria de Atenção à Saúde. Departamento de Atenção Básica. Política Nacional de Práticas Integrativas e Complementares no SUS, cit.

(67) Os termos práticas integrativas e complementares são decorrentes da Pnpic; como área de conhecimento, seria mais adequado medicina alternativa e práticas tradicionais.

(68) MINISTÉRIO DA SAÚDE. Secretaria de Atenção à Saúde. Departamento de Atenção Básica. Política Nacional de Práticas Integrativas e Complementares no SUS, cit. 
A Pnpmf amplia as opções terapêuticas seguras, eficazes e com qualidade acessível aos usuários - plantas medicinais, fitoterápicos e serviços relacionados à fitoterapia - na perspectiva da integralidade da atenção à saúde e do conhecimento tradicional sobre plantas medicinais ${ }^{(69)}$.

Em relação ao local para exercício das práticas farmacêuticas, a PNAF possibilitou o desenvolvimento de ações para estruturação de farmácias ${ }^{(70)}$ na rede municipal. No entanto, essas ações parecem ser limitantes à luz do direito sanitário: foram estruturadas para um ciclo de AF baseado no medicamento industrializado, podendo até ser fracionado ${ }^{(71)}$, mas sem a inserção de especificidades da assistência farmacêutica decorrente de terapia preconizada na Pnpic e Pnpmf, como planta medicinal(72), droga vegetal| ${ }^{(73)}$, preparação

(69) MINISTÉRIO DA SAÚDE. Secretaria de Ciência, Tecnologia e Insumos Estratégicos. Departamento de Assistência Farmacêutica. Política Nacional de Plantas Medicinais e Fitoterápicos, cit.

(70) MINISTÉRIO DA SAÚDE. Secretaria de Ciência, Tecnologia e Insumos Estratégicos. Departamento de Assistência Farmacêutica e Insumos Estratégicos. Diretrizes para estruturação de farmácias no âmbito do Sistema Único de Saúde. Brasília: Ministério da Saúde, 2009. (Série A. Normas e Manuais Técnicos). Disponível em: <http://portal.saude.gov.br/portal/arquivos/pdf/ diretrizes_para_estruturacao_farmacias_ambito_sus.pdf >. Acesso em: 15 jan. 2013.

(71) Preparação realizada em farmácia ou drogaria sob a supervisão e responsabilidade de profissional farmacêutico habilitado, para atender à prescrição ou ao tratamento correspondente nos casos de medicamentos isentos de prescrição, caracterizado pela subdivisão de um medicamento em frações individualizadas, a partir de sua embalagem original, sem rompimento da embalagem primária, mantendo seus dados de identificação. AGÊNCIA NACIONAL DE VIGILÂNCIA SANITÁRIA. Resolução RDC $\mathrm{n}^{\circ}$ 80, de 11 de maio de 2006. "Dispõe sobre o Regulamento Técnico sobre fracionamento de medicamentos". Disponível em: < http://www.anvisa.gov.br/fracionamento/rdc. htm>. Acesso em: 15 jan. 2013.

(72) Espécie vegetal, cultivada ou não, utilizada com propósitos terapêuticos. AGÊNCIA NACIONAL DE VIGILÂNCIA SANITÁRIA. Resolução RDC $n^{\circ}$ 10, de 9 de março de 2010. "Dispõe sobre a notificação de drogas vegetais junto à ANVISA e dá outras providências". Disponível em: <http:// www.in.gov.br/visualiza/index.jsp? jornal=1\&pagina=52\&data=10/03/2010>. Acesso em: 15 jan. 2013. (73) Planta medicinal ou suas partes, para uso episódico, oral ou tópico, para o alívio sintomático das doenças que contenham as substâncias, ou classes de substâncias, responsáveis pela ação terapêutica, após processos de coleta ou colheita, estabilização, secagem, podendo ser íntegra, rasurada ou triturada. AGÊNCIA NACIONAL DE VIGILÂNCIA SANITÁRIA. Resolução RDC $n^{\circ} 10$, de 9 de março de 2010, cit. 
magistral $^{(74)}$, farmacopeica ${ }^{(75)}$, derivada/transformada(76), unitarizada ${ }^{(77)}$. Isso sugere que o modelo de farmácia no SUS segue um estereótipo decorrente da medicina conservadora-convencional, havendo risco de manter acesso limitado a recursos terapêuticos.

O serviço de farmácia deve ser referência para informações técnico-científicas sobre medicamentos para a saúde local e seus profissionais, seja por meio de acesso a fontes bibliográficas ou eletrônicas confiáveis, acesso remoto a CIMs, seja por publicação de boletim informativo ${ }^{(78)}$.

A informação e a promoção dos medicamentos podem influenciar a maneira pela qual são utilizados; por isso a necessidade de que qualquer medicamento venha acompanhado de informação qualificada. Essas premissas vão ao encontro da principal meta de um CIM: a promoção do $\operatorname{URM}^{(79)}$.

A informação sobre medicamentos pode ser entendida como a provisão de informação obtida em fontes confiáveis, internacionalmente reconhecidas, e contendo dados seguros, independentes e atualizados; adequadamente referenciados, criticamente avaliados e imparciais sobre quaisquer aspectos relacionados à prática farmacêutica; imune a pressões políticas e econômicas; respondida com agilidade e em tempo hábil para a conduta terapêutica; elaborada e comunicada em locais estruturados e organizados chamados centros de informação, auxiliando a tomada de decisão sobre acesso e URM pelos

(74) Elaborada na farmácia, a partir de uma prescrição de profissional habilitado, destinada a um paciente individualizado, e que estabeleça em detalhes sua composição, forma farmacêutica, posologia e modo de usar.AGÊNCIA NACIONAL DE VIGILÂNCIA SANITÁRIA. Resolução RDC $n^{\circ}$ 67, de 8 de outubro de 2007. "Dispõe sobre Boas Práticas de Manipulação de Preparações Magistrais e Oficinais para Uso Humano em farmácias". Disponível em: <http://www.anvisa.gov.br/ legis/resol/2007/rdc/67_081007rdc.htm>. Acesso em: 15 jan. 2013.

(75) Elaborada na farmácia, cuja fórmula esteja inscrita no Formulário Nacional ou em Formulários Internacionais reconhecidos pela Anvisa. AGÊNCIA NACIONAL DE VIGILÂNCIA SANITÁRIA. Resolução RDC $n^{\circ} 67$, de 8 de outubro de 2007, cit.

(76) Preparação manipulada de especialidade farmacêutica visando ao preparo de uma forma farmacêutica a partir de outra. AGÊNCIA NACIONAL DE VIGILÂNCIA SANITÁRIA. Resolução RDC $n^{\circ} 67$, de 8 de outubro de 2007 , cit.

(77) Preparação de doses de medicamento efetuada sob responsabilidade e orientação do farmacêutico, incluindo, fracionamento em serviços de saúde, subdivisão de forma farmacêutica ou transformação/derivação em doses previamente selecionadas, desde que se destinem à elaboração de doses unitarizadas e estáveis por período e condições definidas, visando atender às necessidades terapêuticas exclusivas de pacientes em atendimento nos serviços de saúde. AGÊNCIA NACIONAL DE VIGILÂNCIA SANITÁRIA. Resolução RDC n 67, de 8 de outubro de 2007, cit.

(78) MINISTÉRIO DA SAÚDE. Secretaria de Ciência, Tecnologia e Insumos Estratégicos. Departamento de Assistência Farmacêutica e Insumos Estratégicos. Diretrizes para estruturação de farmácias no âmbito do Sistema Único de Saúde, cit.

(79) MARIN, Nelly; LUIZA, Vera Lucia; OSORIO-DE-CASTRO, Cláudia G. Serpa; MACHADO-DOSSANTOS, Silvio (Orgs.). Assistência farmacêutica para gerentes municipais. Rio de Janeiro: OPAS; OMS, 2003. Disponível em: <http://portal.saude.gov.br/portal/arquivos/pdf/af_gerentes_municipais. pdf>. Acesso em: 15 jan. 2013. 
profissionais de saúde ${ }^{(80),(81),(82)}$.

Desde o reconhecimento do primeiro CIM no mundo(83), as atividades dos centros foram ampliadas para acompanhar o desenvolvimento de novos saberes e práticas em saúde (Quadro 1). ${ }^{(84)}$

No Brasil, iniciativas para criação de centros de informação na década de 1980 culminaram com a criação do Centro Brasileiro de Informação sobre Medicamentos (Cebrim), em 1992, cujos cursos realizados entre 1994 e 1997 foram determinantes para criação de outros centros no país ${ }^{(85)}$.

O número de $\mathrm{CIMs}$ em funcionamento no país atualmente é impreciso. O Conselho Federal de Farmácia (CFF) mantém lista com 22 centros cadastrados $^{(86)}$. No entanto, durante os Fóruns da Rede Brasileira de Centros e Serviços de Informação sobre Medicamentos (Rebracim), em 2010(87) e em 2011(18), participaram 26 centros, 16 dos quais cadastrados no CFF(89).

Analisando as informações disponíveis no sítio eletrônico do $\mathrm{CFF}^{(90)}$ e da Rebracim ${ }^{(91)}$ mais os relatos dos participantes ouvidos pelo autor durante os fóruns da Rede, a diversidade de práticas na atuação dos centros no país, desde a década de 1990, permite reflexões como:

- alguns centros ampliaram o escopo de ação: a temática uso racional passou a contemplar insumos, plantas medicinais e drogas vegetais e algumas terapias integrativas foram inseridas;

(80) FISCHER, Maria Isabel et. al. op. cit.

(81) MARIN, Nelly; LUIZA, Vera Lucia; OSORIO-DE-CASTRO, Cláudia G. Serpa; MACHADO-DOSSANTOS, Silvio (Orgs.). op. cit.

(82) MALONE, Patrick M.; KIER, Karen L.; STANOVICH, John L. Drug information: a guide for pharmacists. 3. ed. New York: McGraw-Hill, 2006.

(83) Universidade de Kentucky, em 1962. (MARIN, Nelly; LUIZA, Vera Lucia; OSORIO-DE-CASTRO, Cláudia G. Serpa; MACHADO-DOS-SANTOS, Silvio (Orgs.). op. cit.).

(84) MARIN, Nelly; LUIZA, Vera Lucia; OSORIO-DE-CASTRO, Cláudia G. Serpa; MACHADO-DOSSANTOS, (Orgs.). op. cit.

(85) VIDOTTI, Carlos C. F. et al. Centro de informação sobre medicamentos: análise diagnóstica do Brasil. Brasília: CFF/OPAS/Sismed, 2000. Disponível em: <http://www.cff.org.br/userfiles/file/ cebrim/2CIM_Brasil_Analise_diagnostica.pdf>. Acesso em: 15 jan. 2013.

(86) CONSELHO FEDERAL DE FARMÁCIA. Cebrim. Outros CIM no Brasil. Disponível em: < http:// www.cff.org.br/pagina.php?id=213\&menu=3\&titulo=Outros+CIM+no+Brasil>. Acesso em: 15 jan. 2013. (87) REDE BRASILEIRA DE SERVIÇOS E CENTROS DE INFORMAÇÃO DE MEDICAMENTOS. I FÓRUM DA REDE BRASILEIRA DE CENTROS E SERVIÇOS DE INFORMAÇÃO SOBRE MEDICAMENTOS - REBRACIM: ESTRATÉGIAS DE INTEGRAÇÃO COM O SUS - 27-28 out. 2010. Disponível em: <http://rebracim.webnode.com.br/foruns/>. Acesso em: 15 jan. 2013.

(88) REDE BRASILEIRA DE SERVIÇOS E CENTROS DE INFORMAÇÃOO DE MEDICAMENTOS. II FÓRUM DA REDE BRASILEIRA DE CENTROS E SERVIÇOS DE INFORMAÇÃO SOBRE MEDICAMENTOS - REBRACIM. A importância de ter acesso à informação independente sobre medicamentos. 06 out. 2011. Disponível em: <http://rebracim.webnode.com.br/foruns/>. Acesso em: 15 jan. 2013.

(89) Informação decorrente da participação do autor durante o II Fórum da Rebracim; a ata final não está disponível.

(90) CONSELHO FEDERAL DE FARMÁCIA. Cebrim. Outros CIM no Brasil, cit.

(91) REDE BRASILEIRA DE SERVIÇOS E CENTROS DE INFORMAÇÃO DE MEDICAMENTOS. Disponível em: <http://rebracim.webnode.com.br/>. Acesso em: 15 jan. 2013. 
Quadro 1: Descrição das atividades de um Centro de Informação sobre Medicamentos, adaptada de Marin ${ }^{(92)}$.

Atividades preconizadas

Responder às perguntas relacionadas ao uso dos medicamentos (atividade principal e essencial, sem a qual não existe o Centro)

Atividades em Comissões, como Comissão de Farmácia e Terapêutica

Publicações: boletins, alertas, colunas em jornais

Educação: estágio, cursos sobre temas específicos da farmacoterapia

Revisão do uso de medicamentos

Atividades de pesquisa sobre medicamentos

Coordenação de programas de notificação (por exemplo, de reações adversas a medicamentos)

- a diversidade de usuários pelo serviço resulta em diversidade de demandas;

- adaptação à demanda por informação é de maneira não coordenada entre os centros e não integrada com as políticas públicas de saúde;

- o financiamento público é necessário para manutenção dos serviços e realização das atividades;

- ainda existem Estados da Federação que não possuem CIM;

- há estados com centros que atendem somente demandas locais ou institucionais, não contemplando as necessidades de toda a sociedade;

- a demanda depende do acesso ao serviço, e o acesso pode estar limitado pela existência de um CIM, horário de funcionamento, público atendido, existência de farmacêutico para elaborar a resposta etc.

Baseado em Malone ${ }^{(93)}$, dentre as etapas descritas para a principal atividade de um CIM - elaboração de respostas -, o processo da informação envolveria, necessariamente: a captação da necessidade real por informação; recebimento da pergunta (demanda); análise de consistência da pergunta; delimitação do tema; seleção de fontes de informação; busca da informação em fontes independentes; elaboração da resposta; validação da resposta; registro no banco de dados; fornecimento da resposta; socialização da informação com o público-alvo; gerenciamento do processo.

A análise de consistência da pergunta se relaciona matricialmente com variáveis - como terapia, tipo de produto regulado ${ }^{(94)}$, consulente, segmento e

(92) MARIN, Nelly; LUIZA, Vera Lucia; OSORIO-DE-CASTRO, Cláudia G. Serpa; MACHADO-DOSSANTOS, Silvio (Orgs.). op. cit.

(93) MALONE, Patrick M.; KIER, Karen L.; STANOVICH, John L. op. cit.

(94) Baseado nos critérios da regulação sanitária da Anvisa e do Ministério da Agricultura: medicamento, alimento, droga vegetal, planta medicinal, cosmético, saneante, produtos para a saúde. 
natureza do estabelecimento, via de recebimento e urgência ${ }^{(95)}$ - que poderiam ajudar na composição das necessidades reais, saberes e práticas sobre um uso racional de medicamentos ampliado, contemplando também insumos, plantas, drogas vegetais, tecnologias e serviços preconizados pelas políticas públicas de saúde.

Embora informação sobre medicamento pareça ser necessária para implementação das políticas de saúde, ainda não foi estruturada com centros de informação inseridos no SUS pelo gestor federal, apesar de a Política Nacional de Medicamentos ter-Ihe atribuído a missão de ser o articulador da AF nas três esferas de governo para promoção do URM e disseminação de informações técnico-científicas.

No campo da saúde, a política pode ser o objetivo da estratégia, e esta, o instrumento da política, em um diálogo circular permanente, dentro de um processo dinâmico para alcançar metas estabelecidas ${ }^{(96)}$.

Sob esse olhar, a Política Nacional de Medicamentos foi estratégica para a elaboração da PNAF e a PNAF foi a estratégia para a implementação da assistência farmacêutica prevista naquela política pública. Pode-se dizer também que a AF é um objetivo da estratégia de informação sobre medicamentos, e esta informação é um dos instrumentos necessários para implementar a Assistência Farmacêutica. Isso concorda com o preconizado pela OMS para a promoção do uso racional de medicamentos ${ }^{(97)}$, pois informação fidedigna e isenta sobre medicamentos é uma das 12 intervenções (estratégias) descritas para sua implementação(98).

Os CIMs foram estruturas contempladas nas diretrizes gerais da $12^{a}$ Conferência Nacional de Saúde em 2003 para possibilitar aos profissionais de saúde acesso à literatura técnico-científica idônea sobre medicamentos e medicação(99). Mas não foram inseridos na PNAF em 2004, como estruturas importantes para o URM.

O pensamento estratégico consiste em destacar a importância da busca permanente de um resultado(100). Se o acesso e uso racional são um resultado a ser alcançado pelas políticas públicas de saúde, então a maneira para alcançá-lo será por meio dessa forma de pensar.

(95) Adaptado de Vidotti (2000), Malone (2006) e do campo de práticas no CIM-RS.

(96) TESTA, Mário. op. cit.

(97) A fonte faz referência a: Uso racional de los medicamentos. Informe de la Conferencia de Expertos. Nairobi, 25-29 de Noviembre de [1985?]. Ginebra, 1986.

(98) ORGANIZAÇÃO PAN-AMERICANA DA SAÚDE. Oficina de trabalho: Uso racional de Medicamentos na perspectiva multiprofissional. Brasília: OPAS/MS/ANVISA, 2007. Disponível em: $<\mathrm{http}: / /$ portal.saude.gov.br/portal/arquivos/pdf/urm_rede_unida.pdf>. Acesso em: 15 jan. 2013.

(99) SISTEMA NACIONAL DE AUDITORIA. 12ª . Conferência Nacional de Saúde. Relatório final. Brasília, 7 a 11 de dezembro de 2003. Brasília: Ministério da Saúde, 2004. Disponível em: <http://sna. saude.gov.br/download/rel\%20final\%2012a\%20CNS.pdf>. Acesso em: 15 jan. 2013.

(100) TESTA, Mário. op. cit. 
Nesse contexto, se a prática das políticas através da PNAF, Pnpic e Pnpmf puder ampliar os conceitos iniciais de acesso e URM, contemplando produtos (medicamentos e suas especificidades, insumos farmacêuticos, plantas e drogas vegetais), tecnologias (como equipamentos de diagnóstico) e serviços (como atenção farmacêutica, atendimento domiciliar, procedimentos farmacotécnicos) necessários à execução integral da AF; se a busca por informação não puder ser suprida localmente na atenção básica; se for possível considerar que a medicina baseada em evidências foi ampliada para saúde baseada em evidências ${ }^{(101)}$, para dar robustez a esse acesso e uso racional ampliado, então os centros de informação são o pensamento estratégico para contribuir ao ciclo de práticas farmacêuticas na $\mathrm{AF}^{(102)}$ do SUS, fornecendo informação útil às novas necessidades, saberes e práticas inseridas nas políticas públicas de saúde.

Nesse sentido, os CIMs são e estão estratégicos para o ciclo da AF no SUS e, por extensão, são ferramentas úteis para a garantia do direito à saúde. Para racionalização do processo de informação à elaboração de respostas, produção de informação técnica e auxílio à tomada de decisão sobre produtos, tecnologias e serviços na AF, a existência de CIMs estruturados para atendimento da complexidade do sistema pode auxiliar na gestão dos seguintes aspectos:

- custos: recursos para aquisição, atualização, manutenção e disponibilidade de fontes de informação na rede;

- informação: habilidades e competências para manejo das fontes, análise da pergunta e fornecimento da informação útil ao demandante;

- pessoas: realocação de especialistas dedicados para as demandas;

- tempo: melhor aproveitamento da hora/atividade dos sujeitos que necessitam da informação e daqueles que a fornecem;

- tecnológico: investimento em novas ferramentas para obtenção, manutenção, gerenciamento e divulgação da informação;

- conhecimento: avaliação permanente das demandas por informação, verificando a necessidade de ações em educação, treinamento, capacitação em saúde ou busca ativa das necessidades reais por informação;

- gerencial: o operador e o gestor da saúde dialogam com critérios epidemiológicos e técnicos, visando assegurar segurança, eficácia, e custo-efetividade

(101) O autor entende que "saúde baseada em evidências" é mais abrangente do que "medicina baseada em evidências", pois se trata da aplicação do método científico a toda a prática profissional em saúde (não apenas a prática médica [KEINERT, 2006. p 16. cit.]), seja esta ligada a tradições convencionais estabelecidas ou àquelas que ainda não foram submetidas ao escrutínio sistemático científico.

(102) Considera o ciclo da Assistência Farmacêutica de maneira ampliada, pois incorpora os insumos farmacêuticos, as plantas medicinais, drogas vegetais e serviços farmacêuticos e práticas profissionais necessários para contemplar a integralidade em processo das ações em saúde, como a atenção farmacêutica, o atendimento domiciliar, as análises clínicas, toxicológicas, fiscal, bromatológica, de controle, dentre outras. 
das ações; racionalizar e harmonizar o uso de produtos e condutas terapêuticas; delinear indicadores mais próximos das necessidades reais por saúde; e direcionar as políticas públicas de saúde para a plenitude da garantia do direito sanitário para a população.

\section{Porém, pode-se considerar complexa essa inserção na AF:}

A saúde enquanto [sic] questão humana e existencial é uma problemática compartilhada indistintamente por todos os segmentos sociais. Porém as condições de vida e de trabalho qualificam de forma diferenciada a maneira pela qual as classes e seus segmentos pensam, sentem e agem a respeito dela. Isso implica que, para todos os grupos [...] a saúde e a doença envolvem uma complexa interação entre os aspectos físicos, psicológicos, sociais e ambientais da condição humana e de atribuição de significados. [...] Saúde e doença são fenômenos clínicos e sociológicos vividos culturalmente [...]. Portanto, incluindo os dados operacionáveis e junto com conhecimento técnico, qualquer ação de tratamento, de prevenção ou de planejamento deveria estar atenta aos valores, atitudes e crenças dos grupos a quem a ação se dirige. ${ }^{(103)}$

Mesmo com a prática da medicina baseada em evidências e uso dos protocolos clínicos e diretrizes terapêuticas preconizados a partir da Política Nacional de Medicamentos( ${ }^{(104)}$, a oficina de trabalho sobre URM de 2006 ressaltou a desinformação profissional(105) e acadêmica ${ }^{(106)}$, que contribuem para a medicalização e medicamentalização(107), como, prescrição desnecessária, tratamentos ineficazes e inseguros, exacerbação ou prolongamento da doença, aumento de reações adversas, desconforto e dano ao paciente; falta de acesso; aumento de demandas judiciais ou não por medicamentos e perda de confiança do usuário.

Da discussão dos pontos críticos em um cenário ideal sobre situações relacionadas com URM, foram sugeridas propostas de estratégias ${ }^{(108)}$, como a implantação de um sistema nacional de informações sobre medicamentos para atendimento das necessidades de diversos atores relacionados com o SUS.

Mesmo com tais propostas, os CIMs ainda não são considerados importantes para a construção do pensamento estratégico e alcance das metas e

(103) MINAYO, Maria Cecília de Souza. O desafio do conhecimento: pesquisa qualitativa em saúde. 8. ed. São Paulo: Hucitec, 2004. p. 15.

(104) KEINERT, Tânia Margarete Mezzomo; PAULA, Sílvia Helena Bastos de; BONFIM, José Rubem de Alcântara (Orgs.). op. cit.

(105) Relacionado aos profissionais que preferem atuar mais comodamente informados por informação passiva e permeada pelo conflito de interesses, como a dos propagandistas de laboratórios e palestras em congressos, mesmo conhecedores da medicina baseada em evidências. (106) Relacionado à falta de estímulo à busca ativa e à leitura crítica da informação científica; a não incorporação do paradigma das condutas baseadas em evidências à prática médica; e às raras bibliografias existentes baseadas em evidência e isentas.

(107) ORGANIZAÇÃO PAN-AMERICANA DA SAÚDE, 2007. op.cit.

(108) Id. Ibid. 
cumprimento das diretrizes descritas na PNAF, Pnpic e Pnpmf, pois sua inserção formal nessas políticas não ocorreu. Talvez porque os atores que discutem e aprovam propostas nos espaços setoriais não sejam os mesmos que a implementarão; ou aqueles que deveriam implementá-las não estejam representados nesses espaços; ou os sujeitos sociais teoricamente beneficiados com as propostas também não estejam representados e não conseguem informar as suas necessidades reais em saúde; ou condutas ${ }^{(109)}$ de gestão pelos operadores das políticas públicas não dialogam com as propostas aprovadas.

O direito à saúde poderá ser comprometido, se o direito por informação for limitado, com informações fornecidas pelos serviços de farmácia no SUS norteadas pelo modelo convencional hegemônico.

Para evidenciar a limitação da inclusão dos CIMs no SUS, os Fóruns da Rebracim reforçaram a importância da criação de redes de centros de informação para contribuir na continuação do funcionamento destes, pois, embora existam iniciativas anteriores de trabalho conjunto, como o Sismed ${ }^{(110)}$, ainda há dificuldades para captação de financiamento, desenvolvimento de atividades integradas com as políticas públicas de saúde e organização e estrutura inserida na assistência farmacêutica do SUS.

Sugestões para a inserção dos CIMs nas políticas públicas de saúde como estratégia ao acesso e uso racional de medicamentos - extensivamente a produtos, tecnologias e serviços relacionados com a AF no SUS - para contribuição à garantia do direito à saúde da população, são a seguir apresentadas.

\section{PARTICIPAÇÃO SOCIAL}

O processo da informação precisa ser socializado com todos os atores que interagem com ele para a construção de consenso sobre expectativas, necessidades reais, demandas e resultados esperados para o local ou região de abrangência da informação fornecida. Assim, a resposta tende a atender às necessidades de quem usará a informação(111). A participação social em qualquer etapa do processo pode:

- desenvolver nos atores sentimentos de responsabilidade e confiança;

- facilitar o relato de saberes e práticas dos atores, melhorando a percepção

(109) O operador da gestão federal da saúde, por exemplo, tem investido formalmente no Programa Nacional de Telessaúde, o qual está sendo utilizado alternativamente para fornecimento de informação sobre medicamentos na atenção primária. MINISTÉRIO DA SAÚDE. Programa Nacional de Telessaúde Atenção Primária em Saúde. Disponível em: <http://www.telessaudebrasil.org.br>. Acesso em: 15 jan. 2013.

(110) Sistema Brasileiro de Informações sobre Medicamentos (VIDOTTI, Carlos C. F. et al. op. cit.). (111) VIDOTTI, Carlos C. F. et al. op. cit. 
das necessidades reais desses sujeitos pelos CIMs e racionalizando os esforços para a resolução dessas necessidades;

- ser afirmativa e solidária nas fases do processo em que atua, valorizando a iniciativa e a união de esforços para sua concretização;

- possibilitar a multiplicação responsável da informação, ensejando adesão ao processo e agregando-lhe valor;

- ser representativa e efetiva nos espaços interssetoriais da AF no SUS.

\section{ESPAÇO SOCIAL}

As demandas por informação podem provir de indivíduos vinculados a espaços setoriais e interssetoriais da AF, ou de sujeitos formadores de espaços sociais externos. A integração de todos esses espaços formará um espaço social ampliado, global, sobre o qual os efeitos das políticas públicas serão permeados.

Considerando os CIMs inseridos nessa pluralidade, eles podem se constituir em espaços sociais determinantes para subsidiar o delineamento da política de produtos, serviços e tecnologias demandados pela AF no SUS, de modo que:

- esse espaço esteja disponível e acessível para participação representativa de todos os atores com os quais a informação produzida interagirá;

- os atores envolvidos com o processo de informação precisam estar representados nos conselhos de saúde - local de escolha para a visualização e percepção de que os CIMs e suas atividades são estratégicos no SUS;

- a distribuição de forças para defesa de concepções de diferentes atores nos espaços sociais precisa ser garantida.

\section{CONTROLE SOCIAL}

O controle social no SUS é essencial para o processo democrático de representação de forças, defesa e manutenção de direitos, e garantia do cumprimento de deveres constitucionais. Responsável pela inserção das políticas públicas de saúde no contexto social das necessidades reais da população, controle social na saúde vinculado às esferas federal, estadual e municipal tem como competências:

- fiscalizar eficazmente a execução dessas políticas, aliando diferentes técnicas metodológicas e de representação dos atores;

- avaliar criticamente a condução das políticas públicas de saúde para, se necessário, reorientá-las a fim de que atendam a universalidade, integralidade 
e equidade constitucionais preconizadas à saúde e derivem outras políticas, programas e projetos.

\section{SABERES E CAMPO DE PRÁTICAS}

O ciclo da Assistência Farmacêutica contempla saberes e campos de práticas de várias profissões. Deveria ser um ciclo inclusivo, prevendo o desenvolvimento de saberes e práticas necessárias para o cumprimento das políticas públicas de saúde, de modo a garantir a universalidade, integralidade e equidade no acesso e uso racional principalmente de medicamentos através, inclusive, da informação.

No âmbito da farmácia, o ciclo de práticas farmacêuticas poderia estar inserido na AF e, para cada uma dessas práticas e saberes, seria relevante estabelecer o exercício das profissões inter-relacionadas, facilitando a visualização, compreensão e delimitação das responsabilidades, habilidades e competências dos diferentes atores que interagem com essas práticas e saberes. Nesse pensamento, seriam úteis a:

- regulamentação do exercício profissional do serviço farmacêutico realizado em centros de informação e no ciclo de práticas farmacêuticas na Assistência Farmacêutica no SUS;

- participação inclusiva dos conselhos profissionais no ciclo de práticas farmacêuticas no SUS para auxílio na resolução de questões, contemplando a totalidade de práticas desenvolvidas no âmbito de cada exercício profissional.

\section{DIRETRIZES}

Para contribuição ao direito à saúde, são propostas as seguintes diretrizes para estruturação de centros de informação sobre medicamentos no âmbito do SUS:

- hierarquização: consideração da complexidade dos serviços disponíveis pelos CIMs e a diversidade de ações e áreas temáticas desses serviços, através de modelo matricial e reticular de referência e contrarreferência, estruturados em níveis de serviços de informação, de menor complexidade - atendimento local - ao de maior complexidade - abrangência nacional -, podendo contribuir para a racionalização de custos, alocação de pessoas e desenvolvimento de informação ativa pelos CIMs;

- regulação: visualização dos serviços de informação como locais fisicamente constituídos para o exercício profissional do farmacêutico, através de adequação perante órgãos reguladores, como regularidade técnica e sanitária e certificação em boas práticas; 
- infraestrutura, organização e funcionamento: definição de requisitos mínimos para área física, equipamentos, mobiliário, recursos tecnológicos, acesso e disponibilidade de fontes obrigatórias, horário de atendimento, lista de serviços mínimos, atividades de inclusão social, integração com atividade de ensino, pesquisa e extensão universitária, dentre outros aspectos, de modo que hajam exigências mínimas para cada nível de complexidade. É imprescindível farmacêutico dedicado para resolução das perguntas durante todo horário de funcionamento do CIM; é recomendável que os serviços de maior complexidade estejam localizados ou formalmente vinculados com instituições de ensino superior para desenvolvimento de atividades conjuntas em pesquisa, ensino e extensão universitária;

- financiamento: através do bloco da Assistência Farmacêutica(112), pois a informação sobre insumos, plantas e medicamentos é intrínseca à AF;

- racionalização do processo: o atendimento das necessidades reais por informação, através da busca ativa por atividade exploratória, observacional, ou estimulada pelo profissional de saúde, preferencialmente no espaço social de que o indivíduo que utiliza produtos, tecnologias e serviços participa, contribui com resultados mais próximos da realidade por informação, refletindo em indicadores mais confiáveis sobre acesso e uso racional e repercutindo em práticas mais eficazes;

- universalidade e integralidade: todos os atores que necessitam de informação têm direito de acessá-la e obtê-la. No entanto, a informação precisa ser organizada e disponível em níveis de acesso, para facilitar sua compreensão e adesão às práticas dela decorrentes;

- equidade: a informação fornecida deve atender às necessidades reais dos sujeitos, respeitando e adequando-se a elas;

- ausência de vieses: depende de fatores, como (1) ausência de conflito de interesse do profissional processador da informação; (2) seleção de fontes de informação seguindo critérios técnicos para garantir a idoneidade do conteúdo e atender à demanda epidemiológica no âmbito do serviço; e (3) modelo de gestão que garanta a participação representativa de todos os atores relacionados com o serviço, contribuindo para a transparência nas decisões estratégicas do gestor responsável pelo CIM e dialogando com a universalidade, integridade e equidade das políticas públicas;

- banco de dados: é necessário um sistema de informação gerencial para a gestão de usuários, demandas, respostas, estatísticas, indicadores de qualidade e relatórios para monitoramento e avaliação do processo de todos os serviços referenciados sobre informação no SUS. O banco de dados precisa ser

(112) MINISTÉRIO DA SAÚDE. Portaria GM/MS n 399, de 22 de fevereiro de 2006. "Divulga o Pacto pela Saúde 2006 - Consolidação do SUS e aprova as Diretrizes Operacionais do referido Pacto". Disponível em: <http://bvsms.saude.gov.br/bvs/publicacoes/prtgm399_20060222.pdł. Acesso em: 15 jan. 2013. 
confiável, padronizado e seguro; deve permitir seu acesso remoto, rastreabilidade e atualização sistêmica (online) e instantânea (real time); deve ser integrado e acessível a todos os níveis de serviço, através de patamares de permissão para acesso às informações;

- publicidade: divulgação das ações desenvolvidas pelos CIMs em espaços de acesso público;

- gestão do conhecimento: o conhecimento produzido pelos serviços de informação pode contribuir para o planejamento estratégico sobre a condução e necessidades das políticas públicas de saúde para o acesso e uso racional, integrando este conhecimento ao campo de práticas da Assistência Farmacêutica no SUS; para a formação acadêmica, científica e tecnológica de profissionais da área da saúde; para ações de ensino, pesquisa e extensão universitária; e para ações inclusivas no ensino médio e fundamental.

\section{CONSIDERAÇÕES FINAIS}

A análise sobre a inserção dos CIMs nas políticas públicas de saúde como estratégia para o acesso e uso racional de medicamentos com universalidade, integralidade e equidade facilita muitas reflexões.

Foi possível observar que a via de acesso e o uso racional de medicamentos descritos nas políticas farmacêuticas analisadas parecem valorizar aspectos que não contemplam efetivamente os princípios constitucionais de universalidade e integralidade da saúde no SUS.

Constatou-se que os CIMs não estão inseridos formalmente na Assistência Farmacêutica do SUS, embora informação sobre medicamentos seja diretriz transversal de políticas públicas de saúde.

Em um cenário de defesa ao direito pleno à saúde, a garantia desse atendimento necessita que o uso de produto, serviço ou tecnologia preconizado pela AF do SUS esteja baseado em evidências, acessível e disponível na rede, de modo a garantir a individualidade da terapia prescrita (planta medicinal, droga vegetal, medicamento e suas especificidades - preparação farmacopeica, derivada/transformada, unitarizada, magistral, fracionada, ou outra); e que o paciente possa escolher o modelo terapêutico de sua crença para seu tratamento, do convencional a outros.

Para que o indivíduo tenha garantido seu direito constitucional à saúde, todos os atores que atuam no SUS - principalmente os profissionais de saúde - devem ter garantia de acesso e obtenção de informações técnico-científicas criticamente avaliadas sobre todos os campos de práticas e modelos terapêuticos reconhecidos pelo SUS. 
Nesse sentido, os centros de informação sobre medicamentos são estratégicos para todo o campo de práticas da Assistência Farmacêutica, pois estão estruturados e organizados para fornecerem informação qualificada e criticamente avaliada para diversos atores, e podem atuar na educação em saúde, atividades de extensão universitária e na pesquisa, contribuindo estrategicamente com o acesso e uso racional em construção no SUS.

Os CIMs podem auxiliar cada etapa do ciclo da Assistência Farmacêutica, podendo contribuir, por exemplo, com a diminuição de demandas judiciais de usuários que não conseguem a garantia do direito no próprio SUS ao acesso e uso racional de medicamentos, serviços e tecnologias.

O trabalho apresenta propostas inclusivas para que os CIMs sejam integrados de forma estratégica no SUS, principalmente na Assistência Farmacêutica, possibilitando que suas atividades sejam compreendidas e valorizadas pelos atores sociais da saúde e do direito.

Essas propostas podem ser incubadoras para revisão da atual PNAF, de modo a fortalecê-la e torná-la efetivamente universalizada e integrada, respondendo às necessidades da população por saúde.

Garantir o direito à saúde contempla o direito integral e universal ao acesso a terapias e a medicamentos disponíveis nas diversas tecnologias farmacêuticas reconhecidas para atendimento da prática terapêutica escolhida, contribuindo para o seu uso racional. A informação técnica qualificada fornecida pelos CIMs pode auxiliar significativamente na garantia desse direito.

\section{REFERÊNCIAS}

AITH, Fernando Mussa Abujamra. Consolidação do direito sanitário no Brasil. In: COSTA, Alexandre Bernardino et al (Orgs.). O Direito achado na rua: introdução crítica ao direito à saúde. Brasília: CEAD/UnB, 2008. p. 65-75.

BONFIM, José Ruben de Alcântara; MERCUCCI, Vera Lúcia (Orgs.). A construção da política de medicamentos. São Paulo: Hucitec; SOBRAVIME, 1997.

CONSELHO FEDERAL DE FARMÁCIA. Cebrim. Outros CIM no Brasil. Disponível em: <http://www.cff.org.br/pagina.php?id=213\&menu=3\&titulo=Outros+C IM+no+Brasil>. Acesso em: 15 jan. 2013.

CONSELHO NACIONAL DE SAÚDE. $1^{\text {a }}$. CONFERÊNCIA NACIONAL DE MEDICAMENTOS E ASSISTÊNCIA FARMACÊUTICA. Relatório final. Brasília: Ministério da Saúde, 2005. Série D. Reuniões e Conferências. Disponível em: <http://conselho.saude.gov.br/biblioteca/Relatorios/confer_nacional_de\%20 medicamentos.pdf >. Acesso em: 15 jan. 2013. 
CONSELHO NACIONAL DE SAÚDE. $8^{\mathrm{a}}$. Conferência Nacional de Saúde. Relatório final. Brasília, 17 a 21 de Março de 1986. Brasília: Ministério da Saúde / Ministério da Previdência e Assistência Social. Disponível em: <http://conselho. saude.gov.br/biblioteca/Relatorios/relatorio_8.pdf>. Acesso em: 15 jan. 2013.

CZERMAINSKI, Sílvia Beatriz Costa. A política nacional de plantas medicinais e fitoterápicos: um estudo a partir da análise de políticas públicas. 2009. $82 \mathrm{f}$. Dissertação (Mestrado em Ciências Farmacêuticas) - Universidade Federal do Rio Grande do Sul, Porto Alegre, 2009.

DALLARI, Sueli Gandolfi. O conteúdo do direito à saúde. In: COSTA, Alexandre Bernardino et al (Orgs.). O direito achado na rua: introdução crítica ao direito à saúde. Brasília: CEAD; Ed. da UnB, 2008. p. 91-101.

DELDUQUE, Maria Célia; OLIVEIRA, Mariana S. de Carvalho. Tijolo por tijolo: a construção permanente do direito à saúde. In: COSTA, Alexandre Bernardino et al (Orgs.). O direito achado na rua: introdução crítica ao direito à saúde. Brasília: CEAD; Ed. da UnB, 2008. p. 103-111.

DÍAZ BERMÚDEZ, Ximena Pamela et al. O Sistema Único de saúde, uma retrospectiva e principais desafios. In: COSTA, Alexandre Bernardino et al (Orgs.). $O$ Direito achado na rua: introdução crítica ao direito à saúde. Brasília: $C E A D /$ UnB, 2008. p. 113-126.

FISCHER, Maria Isabel et. al. CIM-RS: o desafio de qualificar a informação. Porto Alegre: Ed. da UFRGS, 2007.

FORMIGUIERI, Ramon Vinícius. Caracterização dos estabelecimentos de origem das solicitações de informação CIM-RS-2007. 2008. Trabalho apresentado no Salão de Extensão Universitária da UFRGS, Porto Alegre, 2008. Disponível em: <http://www.ufrgs.br/boletimcimrs/SUS\%20EXTENSAO\%20-\%20Ramon\%20 2008.pdf>. Acesso em: 15 jan. 2013.

GONÇALVES, Janaína Barbier. Transcrição de palestra proferida na audiência pública da saúde. Supremo Tribunal Federal, 4 de maio de 2009. Disponível em: <http://www.stf.jus.br/arquivo/cms/processoAudienciaPublicaSaude/anexo/ PGERS.pdf>. Acesso em: 15 jan. 2013.

GUIMARÃES, Reinaldo Felipe Nery. Transcrição de palestra proferida na audiência pública da saúde. Supremo Tribunal Federal, 7 de maio de 2009. Disponível em: <http://www.stf.jus.br/arquivo/cms/processoAudienciaPublicaSaude/anexo/Reinaldo.pdf>. Acesso em: 15 jan. 2013.

JONCHEERE, Kees de. A necessidade e os elementos de uma política nacional de medicamentos. In: BONFIM, José Ruben de Alcântara; MERCUCCI, Vera Lúcia (Orgs.). A construção da política de Medicamentos. São Paulo: Hucitec/ SOBRAVIME, 1997. p. 49-63. 
KEINERT, Tânia Margarete Mezzomo; PAULA, Sílvia Helena Bastos de; BONFIM, José Rubem de Alcântara (Orgs.). Ações judiciais no SUS e a promoção do direito à saúde. São Paulo: Instituto de Saúde, 2009. Disponível em: <http://www.google. com.br/url?sa=t\&rct=j\&q=www.hgf.ce.gov.br\%2F...\%2F25-versao-eletronica-do-livro-qas-acoes-judici...\&source=web\&cd=2\&ved=0CDMQFjAB\&url=http\%3A\% 2F\%2Fwww.hgf.ce.gov.br\%2Findex.php\%2Fdownloads\%2Fcategory\%2F25-versao-eletronica-do-livro-qas-acoes-judiciais-no-sus-e-a-promocao-do-direito-a-saudeq-\%3Fdownload\%3D18\%253Aversao-eletronica-do-livro-qas-acoes-judiciais-no-sus-e-a-promocao-do-direito-a-saudeq-\&ei=CH31UKKOJJKm9gSDxI HIDQ\&usg=AFQjCNEj3WSusXAmJIB9huEcolxN6LcNAg\&bvm=bv.41018144,d. eWU>. Acesso em: 15 jan. 2013.

LOPES, L.C.; BARBERATO Filho, S.; POLIMENO N.C.; COSTA, A.C.; NAFFAH, Filho M.; CORREA, M.C.; OSORIO-DE-CASTRO, C.G.S. Medicamentos antineoplásicos e ações judiciais: contribuição para o modelo de assistência farmacêutica no SUS. In: SEMINÁRIO DE AVALIAÇÃO Programa de Pesquisa para o Sistema Único de Saúde - PPSUS/SP 2006-2007: rumo à incorporação dos resultados das pesquisas no âmbito do SUS/SP. São Paulo; 2010. Disponível em: <http://portal.saude.sp.gov.br/resources/instituto-de-saude/ppsus/ relatorios-is/seminarios-de-avaliacao-e-acompanhamento-ppsus-sp/seminario_de_avaliacao_e_acompanhamento_ppsus-sp_2006-2007.pdf>. Acesso em: 15 jan. 2013.

MACHADO, Felipe Rangel de Souza. Contribuições ao debate da judicialização da saúde no Brasil. Revista de Direito Sanitário, São Paulo, v. 9, n. 2, p. 73-91, jul./out. 2008.

MALONE, Patrick M.; KIER, Karen L.; STANOVICH, John L. Drug information: a guide for pharmacists. 3. ed. New York: McGraw-Hill, 2006.

MARIN, Nelly; LUIZA, Vera Lucia; OSORIO-DE-CASTRO, Cláudia G. Serpa; MACHADO-DOS-SANTOS, Silvio (Orgs.). Assistência farmacêutica para gerentes municipais. Rio de Janeiro: OPAS; OMS, 2003. Disponível em: http:// portal.saude.gov.br/portal/arquivos/pdf/af_gerentes_municipais.pdf>. Acesso em: 15 jan. 2013.

MINAYO, Maria Cecília de Souza. O desafio do conhecimento: pesquisa qualitativa em saúde. 8. ed. São Paulo: Hucitec, 2004.

MINISTÉRIO DA SAÚDE. Entendendo o SUS. Ministério da Saúde, 2006. Disponível em: <http://portal.saude.gov.br/portal/arquivos/pdf/cartilha_entendendo_o_ sus_2007.pdf>. Acesso em: 15 jan. 2013.

Profissional e Gestor/Medicamentos. Disponível em: <http://portal. saude.gov.br/portal/saude/profissional/area.cfm?id_area $=1000>$. Acesso em: 18 fev. 2013. 
MINISTÉRIO DA SAÚDE. Programa Nacional de Telessaúde Atenção Primária em Saúde. Disponível em: <http://www.telessaudebrasil.org.br>. Acesso em: 15 jan. 2013.

. Secretaria de Atenção à Saúde. Departamento de Atenção Básica. Política Nacional de Práticas Integrativas e Complementares no SUS. 1. ed. Brasília: Ministério da Saúde, 2008. Disponível em: <http://bvsms.saude. gov.br/bvs/publicacoes/pnpic_atitude_ampliacao_acesso.pdf $>$. Acesso em: 15 jan. 2013.

Secretaria de Ciência, Tecnologia e Insumos Estratégicos. Departamento de Assistência Farmacêutica e Insumos Estratégicos. Diretrizes para estruturação de farmácias no âmbito do Sistema Único de Saúde. Brasília: Ministério da Saúde, 2009. (Série A. Normas e Manuais Técnicos). Disponível em: <http://portal.saude.gov.br/portal/arquivos/pdf/diretrizes_para_estruturacao_farmacias_ambito_sus.pdf >. Acesso em: 15 jan. 2013.

Secretaria de Ciência, Tecnologia e Insumos Estratégicos. Departamento de Assistência Farmacêutica e Insumos Estratégicos. Assistência farmacêutica na atenção básica: instruções técnicas para sua organização. 2 . ed. Brasília: Ministério da Saúde, 2006. Série A. Normas e Manuais Técnicos. Disponível em: <http://www.ensp.fiocruz.br/portal-ensp/judicializacao/pdfs/283. pdf>. Acesso em: 15 jan. 2013.

. Secretaria de Ciência, Tecnologia e Insumos Estratégicos. Departamento de Assistência Farmacêutica e Insumos Estratégicos. Diretrizes para estruturação de farmácias no âmbito do Sistema Único de Saúde. Brasília: Ministério da Saúde, 2009. Série A. Normas e Manuais Técnicos. Disponível em: <http://portal.saude.gov.br/portal/arquivos/pdf/diretrizes_para_estruturacao_farmacias_ambito_sus.pdf >. Acesso: 15 jan. 2013.

Secretaria de Ciência, Tecnologia e Insumos Estratégicos. Departamento de Assistência Farmacêutica. Política Nacional de Plantas Medicinais e Fitoterápicos. Brasília: Ministério da Saúde, 2006. (Série B. Textos Básicos de Saúde). Disponível em: <http://bvsms.saude.gov.br/bvs/publicacoes/politica_nacional_fitoterapicos.pdf>. Acesso em: 15 jan. 2013.

. Secretaria de Políticas de Saúde. Departamento de Atenção Básica. Política Nacional de Medicamentos. Brasília: Ministério da Saúde, 2001. [Série C. Projetos, Programas e Relatórios, n. 25]. Disponível em: <http://bvsms. saude. gov.br/bvs/publicacoes/politica_medicamentos.pdf>. Acesso em: 15 jan. 2013.

MOTA, Daniel Marques et al. Uso racional de medicamentos: uma abordagem econômica para tomada de decisões. Ciência \& Saúde Coletiva, Rio de Janeiro, v. 13, supl. 0, abr. 2008. Disponível em: <http://www.scielosp.org/scielo. php? script=sci_arttext\&pid=S1413-81232008000700008\&lng=pt\&nrm=iso $>$. Acesso em: 15 jan. 2013. http://dx.doi.org/10.1590/S1413-81232008000700008. 
ORGANIZAÇÃO PAN-AMERICANA DA SAÚDE. Oficina de trabalho: Uso racional de Medicamentos na perspectiva multiprofissional. Brasília: OPAS/MS/ ANVISA, 2007. Disponível em: <http://portal.saude.gov.br/portal/arquivos/pdf/ urm_rede_unida.pdf>. Acesso em: 15 jan. 2013.

Uso racional de medicamentos y otras tecnologías de salud. Disponível em: < http://new.paho.org/hq/index.php?option=com_content\&view=category\&l ayout=blog\&id=1268\&ltemid=1180>. Acesso em: 15 jan. 2013.

PASCALICCHIO, Áurea Eleutério. A necessidade de uma medicina holística. In: BONFIM, José Ruben de Alcântara; MERCUCCI, Vera Lúcia (Orgs.). A construção da política de medicamentos. São Paulo: Hucitec; SOBRAVIME, 1997. p. 219-221.

PICON, Paulo Dornelles. Transcrição de palestra proferida na audiência pública da saúde. Supremo Tribunal Federal, 4 maio de 2009. Disponível em: <http:// www.stf.jus.br/arquivo/cms/processoAudienciaPublicaSaude/anexo/Paulo_Picon.pdf>. Acesso em: 15 jan. 2013.

REDE BRASILEIRA DE SERVIÇOS E CENTROS DE INFORMAÇÃO DE MEDICAMENTOS. Disponível em: <http://rebracim.webnode.com.br/>. Acesso em: 15 jan. 2013.

I FÓRUM DA REDE BRASILEIRA DE CENTROS E SERVIÇOS DE INFORMAÇÃO SOBRE MEDICAMENTOS - REBRACIM: ESTRATÉGIAS DE INTEGRAÇÃO COM O SUS - 27-28 out. 2010. Disponível em: <http://rebracim. webnode.com.br/foruns/>. Acesso em: 15 jan. 2013.

. II FÓRUM DA REDE BRASILEIRA DE CENTROS E SERVIÇOS DE INFORMAÇÃO SOBRE MEDICAMENTOS - REBRACIM. A importância de ter acesso à informação independente sobre medicamentos. 06 out. 2011. Disponível em: <http://rebracim.webnode.com.br/foruns/>. Acesso em: 15 jan. 2013.

SISTEMA NACIONAL DE AUDITORIA. 12ª . Conferência Nacional de Saúde. Relatório final. Brasília, 7 a 11 de dezembro de 2003. Brasília: Ministério da Saúde, 2004. Disponível em: <http://sna.saude.gov.br/download/rel\%20final\%20 12a\%20CNS.pdf>. Acesso em: 15 jan. 2013.

TERRA, Osmar Gasparini. Transcrição de palestra proferida na audiência pública da saúde. Supremo Tribunal Federal, 29 de abril de 2009. Disponível em: <http://www.stf.jus.br/arquivo/cms/processoAudienciaPublicaSaude/anexo/ Sr_Osmar_Terra.pdf>. Acesso em: 15 jan. 2013.

TESTA, Mário. Pensamento estratégico e lógica de programação: o caso da saúde. São Paulo: Hucitec; Rio de Janeiro: ABRASCO, 1995. 
VIDOTTI, Carlos C. F. et al. Centro de informação sobre medicamentos: análise diagnóstica do Brasil. Brasília: CFF/OPAS/Sismed, 2000. Disponível em: $<$ http://www.cff.org.br/userfiles/file/cebrim/2CIM_Brasil_Analise_diagnostica. pdf>. Acesso em: 15 jan. 2013.

VIEIRA, Fabíola Sulpino; ZUCCHI, Paola. Distorções causadas pelas ações judiciais à política de medicamentos no Brasil. Revista de Saúde Pública, São Paulo, v. 41, n. 2, p. 214-222, 2007. 